\title{
A saposin-lipoprotein nanoparticle system for membrane proteins
}

\author{
Jens Frauenfeld ${ }^{1,10}$, Robin Löving ${ }^{2}$, Jean-Paul Armache ${ }^{3}$, Andreas F-P Sonnen ${ }^{4,5}$, Fatma Guettou ${ }^{1}$, Per Moberg ${ }^{1}$, \\ Lin Zhu ${ }^{6,7}$, Caroline Jegerschöld ${ }^{6,7}$, Ali Flayhan ${ }^{8}$, John A G Briggs ${ }^{4,5}$, Henrik Garoff ${ }^{2}$, Christian Löw ${ }^{1,8}$, \\ Yifan Cheng ${ }^{3,9} \&$ Pär Nordlund ${ }^{1}$
}

\begin{abstract}
A limiting factor in membrane protein research is the ability to solubilize and stabilize such proteins. Detergents are used most often for solubilizing membrane proteins, but they are associated with protein instability and poor compatibility with structural and biophysical studies. Here we present a saposin-lipoprotein nanoparticle system, Salipro, which allows for the reconstitution of membrane proteins in a lipid environment that is stabilized by a scaffold of saposin proteins. We demonstrate the applicability of the method on two purified membrane protein complexes as well as by the direct solubilization and nanoparticle incorporation of a viral membrane protein complex from the virus membrane. Our approach facilitated high-resolution structural studies of the bacterial peptide transporter PeptT $_{\mathrm{S}_{2} 2}$ by single-particle cryo-electron microscopy (cryo-EM) and allowed us to stabilize the HIV envelope glycoprotein in a functional state.
\end{abstract}

Membrane proteins are encoded by approximately $30 \%$ of all open reading frames ${ }^{1}$. Membrane proteins have essential roles in many cellular processes, such as signal transduction, cellto-cell communication, membrane transport and lipid and energy metabolism, and they represent the targets of more than $60 \%$ of drugs in clinical use ${ }^{2}$. However, membrane proteins are difficult to study because of their instability and tendency to aggregate when extracted from their natural lipid-bilayer environment. In order to maintain their integrity, an artificial hydrophobic environment is needed. Detergent micelles are commonly used to solubilize membrane proteins, but they often have adverse effects on protein activity, stability and solubility and can interfere with the experimental setup ${ }^{3-5}$.

A major challenge is maintaining membrane proteins in a lipidlike environment while keeping them stable and monodisperse in solution, so that they become accessible for biochemical, biophysical and structural studies. Methods for reconstituting membrane proteins in lipid nanoparticles, such as liposomes and highdensity lipoprotein particles ${ }^{6,7}$ based on apolipoproteins, also termed nanodiscs, provide a potential solution. These approaches have been used routinely for biochemical and biophysical studies of membrane proteins and have also been applied for structure determination by single-particle cryo-EM ${ }^{8-10}$. However, optimization of the technologies for individual membrane proteins is relatively laborious.

Here we present a lipid nanoparticle system that is based on the saposin protein family. Saposins are known to be modulators of lipid membranes ${ }^{11,12}$, mostly at an acidic $\mathrm{pH}$ within lysosomes. Given their lipid-binding properties, we hypothesized that they could be used to generate a nanoparticle system for the incorporation of membrane proteins (Fig. 1). In this paper we report a methodology for reconstituting membrane proteins in saposin-lipoprotein (Salipro) nanoparticles that allowed us to stabilize fragile membrane protein complexes in detergent-free buffer systems for functional and structural studies.

\section{RESULTS}

\section{Generation of saposin-lipid nanoparticles}

Members of the saposin protein family have membrane-binding and lipid-transport properties ${ }^{11,12}$. Several crystal structures of saposin proteins have been reported, in both the absence and the presence of lipids or detergents ${ }^{13-16}$. It was recently demonstrated that saposin A forms lipid complexes at an acidic lysosomal $\mathrm{pH}$ when incubated with unilamellar liposomes ${ }^{16}$. We therefore rationalized that saposins could be used as scaffolding proteins in a versatile lipid nanoparticle system to reconstitute membrane proteins in a lipid environment, without using liposomes and an acidic $\mathrm{pH}$.

First we tested whether it was possible to incorporate lipids into saposin A complexes without using an acidic $\mathrm{pH}$ or liposomes. We incubated saposin A (Online Methods) with detergent-solubilized phospholipids at physiological $\mathrm{pH} 7.4$ and then removed the

\footnotetext{
${ }^{1}$ Department of Medical Biochemistry and Biophysics, Karolinska Institutet, Stockholm, Sweden. ${ }^{2}$ Department of Biosciences and Nutrition, Karolinska Institutet, Huddinge, Sweden. ${ }^{3}$ Keck Advanced Microscopy Laboratory, Department of Biochemistry and Biophysics, University of California San Francisco, San Francisco, California, USA. ${ }^{4}$ Structural and Computational Biology Unit, European Molecular Biology Laboratory (EMBL), Heidelberg, Germany. ${ }^{5}$ Molecular Medicine Partnership Unit, European Molecular Biology Laboratory-Universitätsklinikum Heidelberg, Heidelberg, Germany. ${ }^{6}$ Department of Biosciences and Nutrition, Karolinska Institutet, Huddinge, Sweden. ${ }^{7}$ School of Technology and Health, Royal Institute of Technology, Novum, Huddinge, Sweden. ${ }^{8}$ EMBL Hamburg, Hamburg, Germany. ${ }^{9}$ Howard Hughes Medical Institute, University of California San Francisco, San Francisco, California, USA. ${ }^{10}$ Present address: Salipro Biotech AB, Södertälje, Sweden. Correspondence should be addressed to J.F. (jens.frauenfeld@salipro.com) or P.N. (par.nordlund@ki.se).

RECEIVED 15 OCTOBER 2015; ACCEPTED 21 JANUARY 2016; PUBLISHED ONLINE 7 MARCH 2016; DOI:10.1038/NMETH.3801
} 
Figure 1 | Salipro nanoparticles stabilize membrane proteins. Incubation of saposin A with lipids and membrane proteins leads to self-assembly of soluble and stable nanoparticles that adjust to the size of the incorporated molecule. Models of saposin-lipid complexes were adapted from PDB IDs 4DDJ, 4APS, 4NCO, 3DIN and 2D0B; virus envelope structure adapted with permission from ref. 48.

detergent via an initial dilution step and subsequent size-exclusion chromatography (SEC) without detergent in the buffer. We observed a considerable shift in the retention time of the saposin A SEC peak after incubation with lipids such as phosphatidylcholine, phosphatidylglycerol, phosphatidylserine and brain lipid extract, supporting the incorporation of lipids to form soluble saposin A-based lipoprotein particles (Fig. 2a). In contrast, no shift was observed after incubation with phosphatidylethanolamine and an Escherichia coli total lipid extract (Supplementary Fig. 1a), indicating a certain degree of lipid preference for saposin A at physiological $\mathrm{pH}^{11}$. Negative-stain electron microscopy of saposin-lipid complexes showed monodisperse particles (Supplementary Fig. 1b). Increasing the lipid-to-saposin ratio led to a slight increase in particle size (Supplementary Fig. 1c). In general, gel-filtration analyses of the saposin-lipid complexes showed symmetric peaks, corresponding to the formation of homogeneous nanoparticle populations. Salipro nanoparticles remained stable after concentration with standard centrifugal filter units. Moreover, particles that had been concentrated and frozen maintained their assembled state as judged by analytical SEC after being thawed and incubated for $10 \mathrm{~min}$ at temperatures from $0-95^{\circ} \mathrm{C}$, indicating a high degree of thermostability (Supplementary Fig. 1d).

\section{Incorporation of membrane proteins into Salipro particles}

Given the Salipro nanoparticles' capacity to integrate detergentsolubilized lipids at physiological $\mathrm{pH}$, we focused on the potential

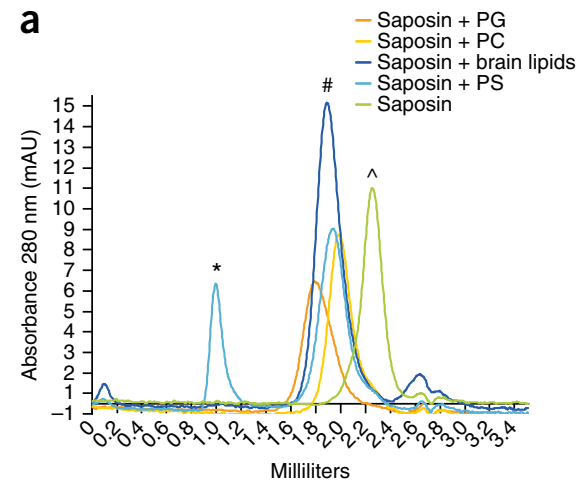

C

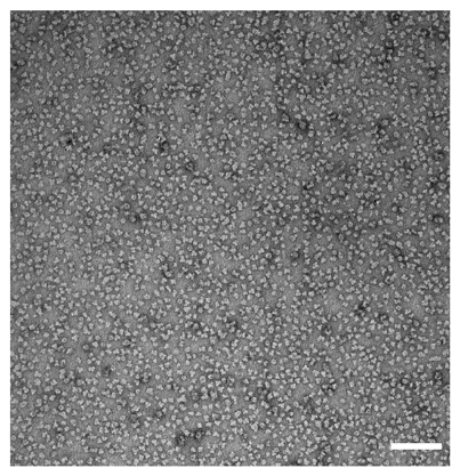

b

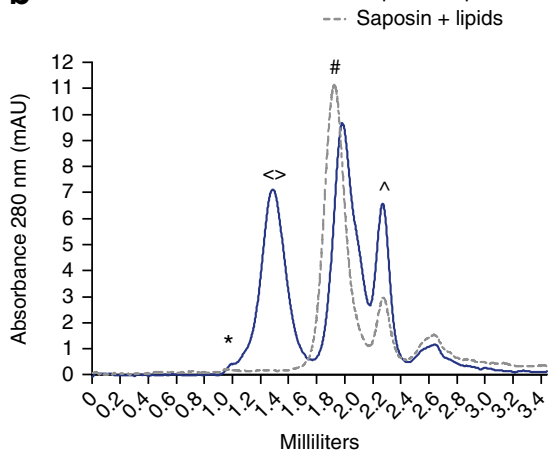

d

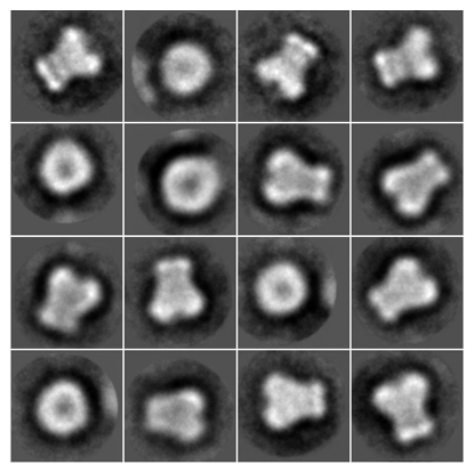

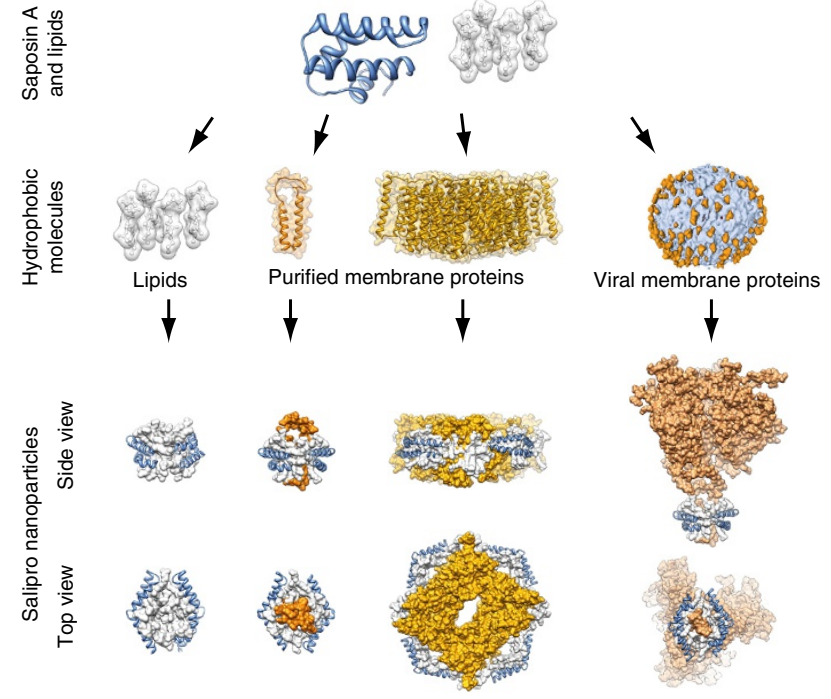

for reconstituting membrane proteins. We incubated detergentpurified membrane proteins with lipids and saposin A and then carried out the detergent-removal steps described above. The model proteins we tested included an archaeal mechanosensitive channel ${ }^{17}$ (T2, 4 predicted transmembrane helices per monomer, $32.9 \mathrm{kDa}$, putative homopentamer) and a bacterial peptide transporter ${ }^{18,19}\left(\mathrm{PepT}_{\mathrm{So} 2}, 14\right.$ transmembrane helices per monomer, $56 \mathrm{kDa}$, homotetramer).

When SEC buffer without detergent is used, these membrane proteins are not soluble but do aggregate and will not elute from the column. In contrast, after incubation with saposin A and lipids, the gel-filtration profile of the archaeal T2 channel showed three symmetric peaks (Fig. 2b); the first peak corresponded to the T2 channel incorporated into Salipro nanoparticles, whereas the second and third peaks originated from lipid-only Salipro nanoparticles and monomeric saposin A, respectively. Thus we concluded that saposin A, lipids and the T2 channel associate in such a way that they form water-soluble particles with incorporated membrane protein.

Peak fractions corresponding to Salipro$\mathrm{T} 2$ were pooled, concentrated and flashfrozen before further analysis via electron microscopy (EM). Salipro-T2 particles that

Figure 2 | Analysis of Salipro particles with lipids and the T2 channel. (a) Gel filtration analysis of saposin A after incubation with the indicated detergent-solubilized lipid solutions. PG, phosphatidylglycerol; PC, phosphatidylcholine; PS, phosphatidylserine. (b) Gel filtration analysis of the incorporation of the pentameric T2 channel into Salipro nanoparticles. *Void volume; ^peaks for monomeric saposin; \#peaks for saposin-lipid complexes; $>$ peaks for Salipro-T2. (c) A representative electron micrograph of T2 in Salipro discs stained with uranyl acetate. Individual side and top views of the reconstituted channel can be seen. Scale bar, $100 \mathrm{~nm}$. (d) Selected 2D class averages of Salipro-T2; the length of each individual box represents $243 \AA$. 
Figure 3 | Single-particle cryo-EM of SaliproPOT. (a) Raw electron micrograph of SaliproPOT collected using a K2 Gatan direct electron camera. Scale bar, $50 \mathrm{~nm}$. (b) Representative 2D class averages generated from the particles; the length of each individual box represents $214 \AA$. (c) Gold-standard FSC between two independently refined half-maps. (d) Selected slice views of the unsharpened 3D density map. The views are oriented parallel to the membrane plane. The number of slices is shown for each view. The length of each individual box represents $184 \AA$. (e) Euler angle distribution of all particles included in the calculation of the final $3 \mathrm{D}$ reconstruction. The size of each sphere is proportional to the number of particles in that specific orientation. (f) Final 3D reconstruction color-coded according to the local resolution ${ }^{49}$, as seen from top (right), sliced parallel to the plane of the membrane (middle) and in a side view cut perpendicularly to the plane of the membrane (right). a

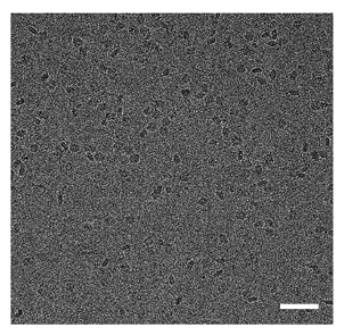

b

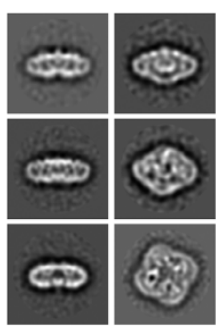

e

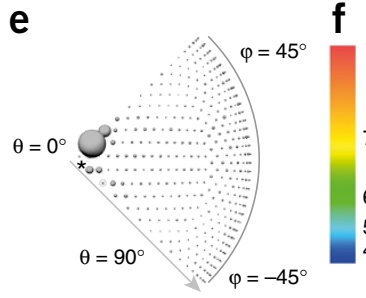

C

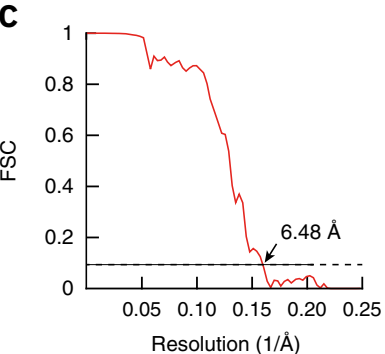

d

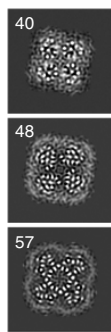

had been concentrated, frozen, thawed and diluted maintained their assembled state as judged by analytical SEC (Supplementary Fig. 2a). Negative-stain EM showed a homogeneous population of single particles that adopted random orientations on the grid (Fig. 2c,d). The particles were more distinct than the T2 channel embedded in micelles of the detergent $n$-dodecyl- $\beta$ - $\mathrm{D}$-malto$\operatorname{side}^{17}$. In side views, both individual particles and two-dimensional (2D) class averages of Salipro-T2 particles displayed two moieties of different sizes, representing a more compact domain and a bilobed domain (Fig. 2d).

\section{Cryo-EM of Salipro-POT}

Proton-coupled oligopeptide transporters (POTs) regulate the uptake of di- and tripeptides and are conserved among all kingdoms of life. We tested our ability to integrate the bacterial peptide transporter PeptTSo2, referred to here as POT, into Salipro nanoparticles. We incubated purified POT with saposin A and lipids. The gel-filtration profile of the bacterial peptide transporter showed three symmetric peaks (Supplementary Fig. 2b), with the first peak corresponding to the membrane protein incorporated into Salipro nanoparticles. Generally, the formation of Salipro particles with incorporated membrane proteins such as POT is feasible within a physiological $\mathrm{pH}$ range (Supplementary Fig. 2c). Prior to further analysis, peak fractions of Salipro-POT were pooled, concentrated and flash-frozen. Thermal unfolding analysis using dye-free differential scanning fluorimetry ${ }^{20}$ showed that the peptide transporter was significantly more stable when embedded in Salipro nanoparticles (melting temperature $\left.\left(T_{\mathrm{m}}\right)=72^{\circ} \mathrm{C}\right)$ than when in the detergent nonyl- $\beta$-Dmaltopyranoside $\left(T_{\mathrm{m}}=43^{\circ} \mathrm{C}\right)$ (Supplementary Fig. 2d).

We used single-particle cryo-EM to determine the structure of POT embedded in Salipro nanoparticles. POT is composed mostly of transmembrane helices and contains only short loop regions that are not embedded in the membrane. Thus there are no significant features outside of the membrane that can be used to align images of the molecules, which makes POT a difficult target for single-particle cryo-EM. We prepared cryo-EM grids of the Salipro-POT complex by the standard plunge-freezing method ${ }^{21}$ at a moderate concentration $\left(0.7 \mathrm{mg} \mathrm{ml}^{-1}\right)$.
Cryo-EM images showed that the frozen hydrated complexes of Salipro-POT were homogeneous and monodisperse (Fig. 3a).

We collected a cryo-EM data set according to established data-acquisition and motion-correction procedures ${ }^{22}$. The 2D class averages displayed the features of secondary and tertiary structures, as well as the tetrameric organization of the peptide transporter (Fig. 3b). Using a total of 9,913 particles, we determined a 3D reconstruction following a gold-standard refinement procedure with fourfold symmetry to a resolution of $6.5 \AA$ (estimated with the criterion ${ }^{23}$ of Fourier shell correlation $($ FSC $)=0.143)$ (Fig. $3 c$ c). All secondary structural features were clearly resolved in the final 3D density map (Fig. 3d). The Euler angle distribution showed that particles were evenly distributed in different orientations in vitreous ice (Fig. 3e). The local resolution in the core region of the nanoparticle, representing the transmembrane helices of the peptide transporter, was significantly higher than that in the regions that could be attributed to the more flexible saposin-lipid scaffold (Fig. 3f and Supplementary Fig. 3). The cryo-EM density revealed a square-shaped disc with overall dimensions of $12 \mathrm{~nm} \times 12 \mathrm{~nm} \times 5 \mathrm{~nm}$ with well-resolved transmembrane helices (Fig. 4a and Supplementary Video 1). Given the size (Fig. 4a) and the apparent stoichiometry (Supplementary Fig. 2e) of Salipro-POT, we can assume that each particle is composed of four POT molecules and four saposin A molecules (Fig. 4a and Supplementary Video 1).

The crystal structure of the peptide transporter ${ }^{19}$ could be directly docked into the cryo-EM density as a rigid body without modification (Fig. 4). Whereas the transmembrane helices were well resolved, the Salipro scaffold of saposin and lipids seemed to be more flexible (Fig. 3f and Supplementary Fig. 3). Fitting of saposin A into the scaffold density was therefore done with a map displayed at a lower isosurface level (Fig. 4a and Supplementary Video 1). The general dimensions of the Salipro scaffold were in agreement with a recently published structure of saposin $\mathrm{A}^{16}$. At the current low resolution for the saposin-lipid belt, we cannot exclude the possibility that saposin might also directly interact with the transmembrane helices of the bacterial transporter. However, we hypothesize that if saposin did indeed 
Figure 4 | Cryo-EM structure of Salipro-POT. (a) 3D density map of the tetrameric bacterial transporter, filtered to $6.5 \AA$, showing each of the subunits and tentative placement of saposin (orange and blue, respectively) in the density. Shown are a top view and a side view cut perpendicularly to the plane of the membrane. (b) Representative views of the cryo-EM density and rigidly fitted $\mathrm{X}$-ray crystallography model (PDB ID 4TPH). (c) Selected side-chain densities of bulky residues such as Arg, Trp, Phe and Tyr.

bind directly to a transmembrane helix, it would be less flexible, and thus in turn it would be possible to resolve the $\alpha$-helices of saposin. This was not the case in the current study; the flexibility and hence lower resolution of the saposin-lipid scaffold did not allow for resolution of the $\alpha$-helices of saposin (Fig. $3 \mathbf{f}$ and Supplementary Fig. 3).

The cryo-EM density allowed for clear identification and positioning of the POT transmembrane helices (Fig. 4b). Moreover, the EM density revealed loop and helix densities that could not be modeled in the crystal structure of this peptide transporter ${ }^{19}$. The map also exhibited bulky side-chain densities from amino acids, the positions of which were in good agreement with the rigid-body fitting of the crystal structure of the peptide transporter (Fig. 4c).

\section{Stabilization of the functional HIV-1 spike protein}

Membrane proteins of enveloped viruses often represent potent antigens that can be used for vaccination ${ }^{24}$. The trimeric HIV-1 envelope glycoprotein (HIV-1 spike), which mediates viral entry into host target cells, is a prominent example, as it is the only viral protein exposed to the immune system by intact HIV-1 particles. The HIV-1 spike is highly unstable in detergent ${ }^{25-27}$ (Supplementary Fig. 4).

We therefore tested our ability to incorporate membrane proteins from a viral membrane using the fragile HIV-1 spike as a model system (Fig. 5a). We established a protocol to extract the HIV-1 spike from the membrane of virus-like particles (VLPs) and reconstitute it in Salipro nanoparticles. We incubated VLPs containing HIV-1 spikes with detergent and saposin A and then a

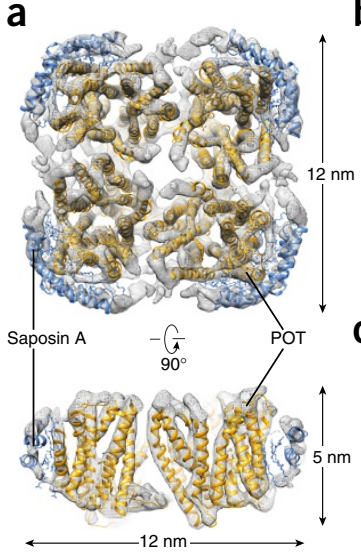

b

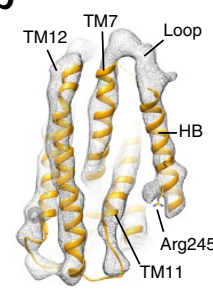

C

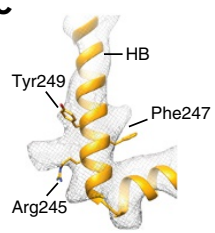

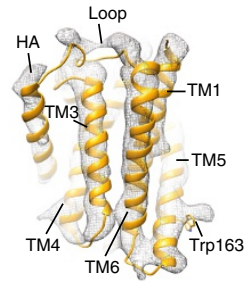

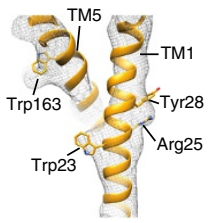

quickly removed detergent micelles using spin SEC columns, thereby forcing the hydrophobic moieties of the initial mixture to self-assemble into Salipro nanoparticles (Salipro-HIV spikes) (Fig. 5b and Supplementary Fig. 5).

Initially we screened six detergents with high critical micelle concentrations. HEGA-10, MEGA-10 and C-HEGA-11 preserved the trimeric HIV-1 spike during solubilization on ice for $10 \mathrm{~min}$, as judged by blue native (BN)-PAGE gel shift assay (Supplementary Fig. 4a). The viral spikes in detergent dissociated completely into monomers within $30 \mathrm{~min}$ at $37^{\circ} \mathrm{C}$ (Supplementary Fig. 4b). To stabilize the trimeric association, we reconstituted the HIV-1 spike in Salipro nanoparticles. We solubilized purified VLPs with 9 mM HEGA-10 in the presence of $0.1 \mathrm{mg} \mathrm{ml}^{-1}$ saposin A (for optimization, see Supplementary Fig. 6) and then removed HEGA-10 using spin SEC columns (Supplementary Fig. 5). BN-PAGE analysis showed that HIV-1 spikes eluted as soluble trimers only in the presence of saposin A, indicating reconstitution in Salipro-HIV spike particles (Fig. 5c). When saposin A was omitted, HIV-1 spikes could not be resolved because of protein aggregation (Fig. 5c).

a

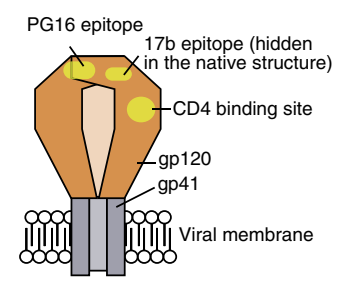

b

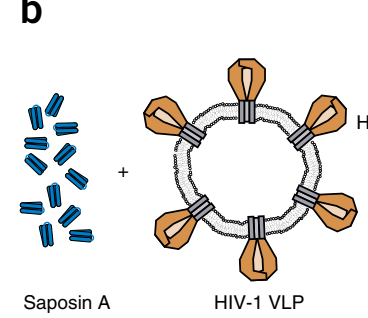

Saposin A
C

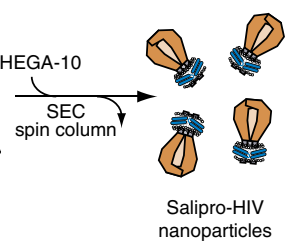

d

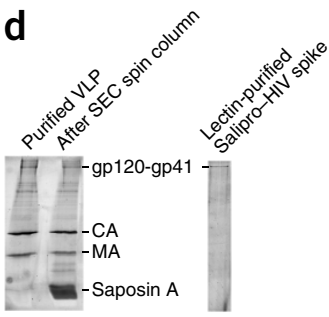

e

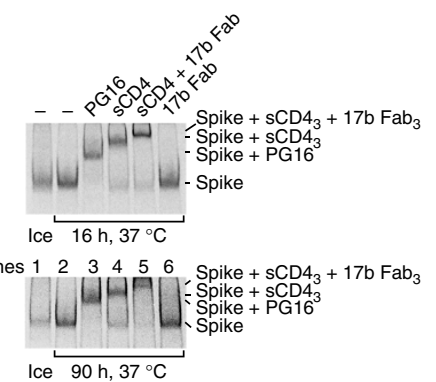

Figure 5 | Stabilization of soluble and functional HIV-1 spike proteins in Salipro nanoparticles.

(a) The HIV-1 spike protein in the viral membrane. The HIV-1 envelope glycoprotein (gp) (i.e., the spike) consists of two subunits, the peripheral gp120 subunit and the transmembrane gp41 subunit, forming a heterotrimer. (b) Salipro-HIV spike reconstitution. Purified VLPs containing HIV-1 spikes (brown) were mixed with saposin A (blue) and solubilized with HEGA-10, and detergent was then removed, leading to the formation of Salipro-HIV spikes. (c) Reconstitution of the HIV-1 spike in Salipro nanoparticles. BN-PAGE analysis showing that the solubility of the HIV-1 spike ( $3 \times \mathrm{gp})$ was maintained by saposin A after detergent removal. (d) Lectin purification of Salipro-HIV spikes. Particle purity was assayed using SDS-PAGE and SYPRO Ruby protein staining. The gels show efficient removal of contaminating viral internal proteins. CA, capsid; MA, matrix. (e) The HIV-1 spike has a native fold and preserves its function in Salipro nanoparticles. Shown are representative gels from BN-PAGE analysis of Salipro-HIV spike particles incubated at $37^{\circ} \mathrm{C}$ for 16 and $90 \mathrm{~h}$ and then at $37^{\circ} \mathrm{C}$ for $2 \mathrm{~h}$ with $10 \mu \mathrm{g} \mathrm{ml}-1$ HIV-1 spike ligands, PG16 (150 kDa) (lane 3), sCD4 (50 kDa) (lane 4), sCD4 and 17b Fab (50 kDa) together (lane 5), $17 \mathrm{~b}$ Fab alone (lane 6 ) or no ligand (lane 2). Lane 1 shows results for a control sample without any ligand that was kept on ice. Binding of the ligands can be followed by the reduced migration of the Salipro-HIV spike particles. 
A second purification step using lectin affinity chromatography successfully removed viral matrix and capsid proteins, as well as excess unbound saposin A, leading to a pure Salipro-HIV spike sample as determined by SDS-PAGE (Fig. 5d and Supplementary Fig. 5).

We investigated the stability and functionality of radiolabeled lectin-purified Salipro-HIV spikes by BN-PAGE. Whereas detergent-solubilized HIV-1 spikes dissociated completely within $30 \mathrm{~min}$ at $37^{\circ} \mathrm{C}$ (Supplementary Fig. 4), Salipro-HIV spikes remained intact for $16 \mathrm{~h}$ and $90 \mathrm{~h}$ at $37^{\circ} \mathrm{C}$ as judged by BN-PAGE (Fig. 5e). Subsequent to the 16-h and 90-h incubations at $37^{\circ} \mathrm{C}$, we assessed the functionality and native features of the Salipro-HIV spikes by binding them to several protein ligands for additional $2 \mathrm{~h}$ at $37^{\circ} \mathrm{C}$. Binding of these ligands to the Salipro-HIV spike increased its apparent molecular weight and therefore decreased its mobility in BN-PAGE correspondingly, as shown before with detergent-HIV-1 spike complexes ${ }^{27}$.

The broadly neutralizing antibody PG16 binds to variable loops V1-V2 and V3 at the top of preferentially intact and functional trimeric HIV-1 spikes ${ }^{27-29}$. We found that PG16 bound efficiently to the Salipro-HIV spikes even after $16-\mathrm{h}$ and 90 -h incubations at $37^{\circ} \mathrm{C}$ (Fig. 5e). In addition, a soluble version of the primary HIV-1 receptor $\mathrm{CD} 4(\mathrm{sCD} 4)$ bound stoichiometrically to the Salipro-HIV spikes (Fig. 5e). Binding of CD4 induces a conformational change in the spike that is essential for binding of the coreceptor site-directed monoclonal antibody $17 \mathrm{~b} \mathrm{Fab}{ }^{30,31}$. We analyzed the binding of $17 \mathrm{~b}$ Fab to Salipro-HIV spike-sCD4 complexes via BN-PAGE, which revealed efficient binding (Fig. 5e). We noted that 17b Fab did not bind to the Salipro-HIV spikes in the absence of sCD4 (Fig. 5e). This confirmed that sCD4 binding induced proper conformational changes to the reconstituted Salipro-HIV spikes. Together, our data demonstrate that the HIV-1 spike can be properly reconstituted in Salipro nanoparticles, preserving the fragile trimeric HIV1 spike structure in a native, stable and functional state for at least $90 \mathrm{~h}$ at $37^{\circ} \mathrm{C}$.

\section{DISCUSSION}

Here we demonstrate that it is possible to incorporate membrane proteins into saposin-based lipid nanoparticles that allow for structural and functional studies of membrane proteins in detergent-free buffer systems. The formation of Salipro nanoparticles is comparably straightforward: lipids are mixed with membrane proteins and saposin $\mathrm{A}$, which leads to a rapid self-assembly reconstitution process. Moreover, it is possible to incorporate viral membrane proteins by mixing saposin A with virus particles, leading to a fully functional viral membrane protein embedded in Salipro nanoparticles.

The nanoparticles are composed of lipids and saposin A, a member of the saposin-like protein family ${ }^{11-16}$. This class of proteins is composed of amphipathic helices and six invariable cysteine residues that form disulfide bridges, leading to extraordinary stability of the domains ${ }^{11}$. We assume that the intrinsic stability of the saposin proteins, which surround the lipid core of the nanoparticle, in turn renders the nanoscale protein-lipid complexes remarkably stable and uniform in a wide temperature range (Supplementary Fig. 1c).

Various methodologies have been developed to stabilize membrane proteins in an aqueous environment ${ }^{7,32-39}$ (Supplementary
Table 1). In efforts to achieve high resolution, both amphipols and maltose-neopentyl glycol-3 analogs have been shown to facilitate structural studies of membrane proteins ${ }^{40,41}$, indicating their stabilizing effect on membrane proteins and their tight binding to the membrane protein. However, these systems do not provide a lipid environment, which is known to be of great importance for membrane protein structure and function.

Discoidal high-density lipoprotein particles, also termed nanodiscs ${ }^{7,42}$, provide a lipid environment, but they do not bind tightly to the transmembrane helices of the membrane protein. Additional apolipoprotein-based nanoparticle systems have been developed that may vary in diameter with respect to the classical nanodisc ${ }^{32,35,39}$. Generally, the size of a nanodisc is dictated by the length of the scaffolding apolipoprotein belt at an optimum lipid content ${ }^{42}$. The classical nanodisc technology was established more than 15 years ago ${ }^{42}$, but so far the application of nanodiscs for single-particle cryo-EM studies has been limited to relatively large targets at subnanometer resolution ${ }^{9,10}$.

The Salipro nanoparticle system combines the advantages of adapting to the size of the incorporated membrane proteins (such as detergents or amphipols) with those of a lipid environment. Moreover, adjustment of the methodology for individual membrane proteins is comparably straightforward. Using the Salipro system, in this study we determined a subnanometer-resolution structure of the POT complex, which is a challenging target for structural studies by single-particle cryo-EM because it contains only short loop regions and has almost no structural features that stick out of the plane of the membrane region. Therefore, our image alignment was driven entirely by the structural features of the transmembrane domain. This may have been facilitated by the relatively small size of the saposin-lipid scaffold, which does not significantly affect the alignment process but enhances the contrast in cryo-conditions (Figs. 3 and $\mathbf{4}$ and Supplementary Fig. $\mathbf{3}$ ).

It has been shown previously that two saposin A molecules can encapsulate a lipid core ${ }^{16}$. Here, in the presence of a large membrane protein complex, we observed that several saposin A proteins may encircle a large hydrophobic lipid-protein assembly in the case of the homotetrameric POT transporter (Fig. 4a and Supplementary Video 1). This suggests significant flexibility of saposin A, allowing it to assemble into homogeneous and stable lipoprotein complexes by adapting to the size of the incorporated molecules. This intrinsic flexibility of saposin A-lipid complexes is likely to facilitate the formation of nanoparticles that can accommodate membrane proteins of different sizes and, at the same time, assist in the formation of homogeneous lipid nanoparticles (Figs. 2-4).

Moreover, we have also presented a method to extract and stabilize fragile membrane proteins from the virus membrane. The HIV-1 spike is the only viral protein that is exposed to the immune system by intact virus particles and therefore is an interesting target for HIV vaccine development ${ }^{24,43,44}$. Antigen candidates that could preserve or sufficiently mimic the native conformation of the HIV-1 spike including the important membrane domain have long been sought after ${ }^{43,44}$. It has been shown that regions proximal to the membrane as well as the membrane domain of the HIV-1 spike are important for the generation of broadly neutralizing antibodies to this virus ${ }^{45-47}$.

To our knowledge, the HIV-1 spike protein preparation presented here using the Salipro system represents the first approach 
that allows for stabilization of the HIV-1 spike, including of the important membrane domains, in a soluble and functional state. Thus, the strategy applied here may represent a novel approach for the generation of immunogen or vaccine candidates that might induce broadly neutralizing antibodies to HIV-1. We envisage that this approach may be applicable to other viral envelope proteins such as influenza virus hemagglutinin, Ebola virus $G$ protein and hepatitis $\mathrm{C}$ virus $\mathrm{E}$ protein.

In summary, Salipro particles provide a versatile nanoparticle platform for membrane proteins and may have a wide range of potential applications, from structural biology to the discovery of new pharmacological agents and the therapeutic delivery of protein-based therapeutics and vaccines.

\section{METHODS}

Methods and any associated references are available in the online version of the paper.

Accession codes. The 3D cryo-EM density map of Salipro-POT has been deposited in the Electron Microscopy Data Bank under accession number 3302 .

Note: Any Supplementary Information and Source Data files are available in the online version of the paper.

\section{ACKNOWLEDGMENTS}

This work was supported by the European Molecular Biology Organization (EMB0) (long-term fellowship to J.F.), the Swedish Research Council (grants 2014-5583 and 2013-3922 to P.N., grant 2013-4621 to H.G. and grant 2010-4483 to C.J.), the Knut and Alice Wallenberg Foundation (grant 2014.0112 to P.N.), the Swedish Cancer Society (grant 130401 to P.N. and grant 140473 to H.G.) the Swedish Childhood Cancer Foundation (grant PR2014-0156 to P.N.), Nanyang Technological University (start-up grant to P.N.), Marie Curie Actions Project FP7-People-ITN-2008 (Virus Entry 235649 to H.G.), Stiftelsen Läkare mot AIDS Forskningsfond (to R.L.), Howard Hughes Medical Institute (Y.C.), the US National Institutes of Health (grants R01GM098672, P50GM082250 and 1S100D020054 to Y.C.), the Karolinska Institutet Center for Biosciences (to C.J.), the China Scholarship Council (fellowship to L.Z.) and the Molecular Medicine Partnership Unit (MMPU) of the University Clinic Heidelberg (A.F.-P.S. and J.A.G.B.) and the European Molecular Biology Laboratory (A.F.-P.S. and J.A.G.B.). We also acknowledge the Protein Science Facility at Karolinska Institutet for cloning assistance and protein purification. Y.C. is an investigator at Howard Hughes Medical Institute.

\section{AUTHOR CONTRIBUTIONS}

J.F. developed the concept, performed experiments, analyzed data and wrote the manuscript. R.L. developed, performed and analyzed HIV-related experiments. J.-P.A. carried out all cryo-EM experiments, including data acquisition, processing and data interpretation. F.G., P.M., A.F. and C.L. purified membrane proteins. A.F.-P.S. prepared grids, collected negative-stain data and conducted image processing on Salipro-T2. C.J. and L.Z. prepared grids and collected negative-stain data on lipid-only Salipro nanoparticles. J.A.G.B., H.G., Y.C. and P.N. contributed project feedback and comments on the manuscript. All authors contributed to data interpretation and preparation of the manuscript.

\section{COMPETING FINANCIAL INTERESTS}

The authors declare competing financial interests: details are available in the online version of the paper.

Reprints and permissions information is available online at http://www.nature. com/reprints/index.html.

1. Wallin, E. \& von Heijne, G. Genome-wide analysis of integral membrane proteins from eubacterial, archaean, and eukaryotic organisms. Protein Sci. 7, 1029-1038 (1998).

2. Overington, J.P., Al-Lazikani, B. \& Hopkins, A. How many drug targets are there? Nat. Rev. Drug Discov. 5, 993-996 (2006).

3. Tate, C.G. Practical considerations of membrane protein instability during purification and crystallisation. Methods Mol. Biol. 601, 187-203 (2010).
4. Breyton, C., Pucci, B. \& Popot, J.L. Amphipols and fluorinated surfactants: two alternatives to detergents for studying membrane proteins in vitro. Methods Mol. Biol. 601, 219-245 (2010).

5. Raschle, T., Hiller, S., Etzkorn, M. \& Wagner, G. Nonmicellar systems for solution NMR spectroscopy of membrane proteins. Curr. Opin. Struct. Biol. 20, 471-479 (2010).

6. Rigaud, J.L. \& Levy, D. Reconstitution of membrane proteins into liposomes. Methods Enzymol. 372, 65-86 (2003).

7. Bayburt, T.H., Carlson, J.W. \& Sligar, S.G. Reconstitution and imaging of a membrane protein in a nanometer-size phospholipid bilayer. J. Struct. Biol. 123, 37-44 (1998).

8. Wang, L. \& Sigworth, F.J. Structure of the BK potassium channel in a lipid membrane from electron cryomicroscopy. Nature 461, 292-295 (2009).

9. Frauenfeld, J. et al. Cryo-EM structure of the ribosome-SecYE complex in the membrane environment. Nat. Struct. Mol. Biol. 18, 614-621 (2011).

10. Efremov, R.G., Leitner, A., Aebersold, R. \& Raunser, S. Architecture and conformational switch mechanism of the ryanodine receptor. Nature 517, 39-43 (2015)

11. Bruhn, H. A short guided tour through functional and structural features of saposin-like proteins. Biochem. J. 389, 249-257 (2005).

12. Olmeda, B., Garcia-Alvarez, B. \& Perez-Gil, J. Structure-function correlations of pulmonary surfactant protein SP-B and the saposin-like family of proteins. Eur. Biophys. J. 42, 209-222 (2013).

13. Ahn, V.E., Faull, K.F., Whitelegge, J.P., Fluharty, A.L. \& Prive, G.G. Crystal structure of saposin B reveals a dimeric shell for lipid binding. Proc. Natl. Acad. Sci. USA 100, 38-43 (2003).

14. Hawkins, C.A., de Alba, E. \& Tjandra, N. Solution structure of human saposin $C$ in a detergent environment. J. Mol. Biol. 346, 1381-1392 (2005).

15. Rossmann, M. et al. Crystal structures of human saposins $C$ and $D$ : implications for lipid recognition and membrane interactions. Structure 16, 809-817 (2008).

16. Popovic, K., Holyoake, J., Pomes, R. \& Prive, G.G. Structure of saposin A lipoprotein discs. Proc. Natl. Acad. Sci. USA 109, 2908-2912 (2012).

17. Löw, C. et al. Nanobody mediated crystallization of an archeal mechanosensitive channel. PLOS ONE 8, e77984 (2013).

18. Guettou, F. et al. Structural insights into substrate recognition in proton-dependent oligopeptide transporters. EMBO Rep. 14, 804-810 (2013).

19. Guettou, F. et al. Selectivity mechanism of a bacterial homolog of the human drug-peptide transporters PepT1 and PepT2. Nat. Struct. Mol. Biol. 21, 728-731 (2014).

20. Alexander, C.G. et al. Novel microscale approaches for easy, rapid determination of protein stability in academic and commercial settings. Biochim. Biophys. Acta 1844, 2241-2250 (2014).

21. Cyrklaff, M., Adrian, M. \& Dubochet, J. Evaporation during preparation of unsupported thin vitrified aqueous layers for cryo-electron microscopy. J. Electron Microsc. Tech. 16, 351-355 (1990).

22. Li, X. et al. Electron counting and beam-induced motion correction enable near-atomic-resolution single-particle cryo-EM. Nat. Methods 10, 584-590 (2013).

23. Scheres, S.H. \& Chen, S. Prevention of overfitting in cryo-EM structure determination. Nat. Methods 9, 853-854 (2012).

24. Plotkin, S.A. \& Plotkin, S.L. The development of vaccines: how the past led to the future. Nat. Rev. Microbiol. 9, 889-893 (2011).

25. Agrawal, N. et al. Functional stability of unliganded envelope glycoprotein spikes among isolates of human immunodeficiency virus type 1 (HIV-1). PLOS ONE 6, e21339 (2011).

26. Leaman, D.P. \& Zwick, M.B. Increased functional stability and homogeneity of viral envelope spikes through directed evolution. PLOS Pathog. 9, e1003184 (2013).

27. Löving, R., Sjoberg, M., Wu, S.R., Binley, J.M. \& Garoff, H. Inhibition of the HIV-1 spike by single-PG9/16-antibody binding suggests a coordinated-activation model for its three protomeric units. J. Virol. 87 7000-7007 (2013).

28. Julien, J.P. et al. Asymmetric recognition of the HIV-1 trimer by broadly neutralizing antibody PG9. Proc. Natl. Acad. Sci. USA 110, 4351-4356 (2013).

29. Walker, L.M. et al. Broad and potent neutralizing antibodies from an African donor reveal a new HIV-1 vaccine target. Science 326, 285-289 (2009).

30. Kwong, P.D. et al. Structure of an HIV gp120 envelope glycoprotein in complex with the CD4 receptor and a neutralizing human antibody. Nature 393, 648-659 (1998). 
31. Thali, M. et al. Characterization of conserved human immunodeficiency virus type 1 gp120 neutralization epitopes exposed upon gp120-CD4 binding. J. Virol. 67, 3978-3988 (1993).

32. Hagn, F., Etzkorn, M., Raschle, T. \& Wagner, G. Optimized phospholipid bilayer nanodiscs facilitate high-resolution structure determination of membrane proteins. J. Am. Chem. Soc. 135, 1919-1925 (2013).

33. Knowles, T.J. et al. Membrane proteins solubilized intact in lipid containing nanoparticles bounded by styrene maleic acid copolymer. J. Am. Chem. Soc. 131, 7484-7485 (2009).

34. McGregor, C.L. et al. Lipopeptide detergents designed for the structural study of membrane proteins. Nat. Biotechnol. 21, 171-176 (2003).

35. Park, S.H. et al. Nanodiscs versus macrodiscs for NMR of membrane proteins. Biochemistry 50, 8983-8985 (2011).

36. Schafmeister, C.E., Miercke, L.J. \& Stroud, R.M. Structure at $2.5 \AA$ of a designed peptide that maintains solubility of membrane proteins. Science 262, 734-738 (1993).

37. Tao, H. et al. Engineered nanostructured $\beta$-sheet peptides protect membrane proteins. Nat. Methods 10, 759-761 (2013).

38. Tribet, C., Audebert, R. \& Popot, J.L. Amphipols: polymers that keep membrane proteins soluble in aqueous solutions. Proc. Natl. Acad. Sci. USA 93, 15047-15050 (1996).

39. Wang, X., Mu, Z., Li, Y., Bi, Y. \& Wang, Y. Smaller nanodiscs are suitable for studying protein lipid interactions by solution NMR. Protein J. 34, 205-211 (2015).
40. Paulsen, C.E., Armache, J.P., Gao, Y., Cheng, Y. \& Julius, D. Structure of the TRPA1 ion channel suggests regulatory mechanisms. Nature 520, 511-517 (2015).

41. Rollauer, S.E. et al. Structure of the TatC core of the twin-arginine protein transport system. Nature 492, 210-214 (2012).

42. Bayburt, T.H. \& Sligar, S.G. Membrane protein assembly into Nanodiscs. FEBS Lett. 584, 1721-1727 (2010).

43. Haynes, B.F. \& Verkoczy, L. AIDS/HIV. Host controls of HIV neutralizing antibodies. Science 344, 588-589 (2014).

44. Kwong, P.D., Mascola, J.R. \& Nabel, G.J. Broadly neutralizing antibodies and the search for an HIV-1 vaccine: the end of the beginning. Nat. Rev. Immunol. 13, 693-701 (2013).

45. Huang, J. et al. Broad and potent neutralization of HIV-1 by a gp41specific human antibody. Nature 491, 406-412 (2012).

46. Muster, T. et al. A conserved neutralizing epitope on gp41 of human immunodeficiency virus type 1. J. Virol. 67, 6642-6647 (1993).

47. Rujas, E. et al. Structural and thermodynamic basis of epitope binding by neutralizing and nonneutralizing forms of the anti-HIV-1 antibody $4 \mathrm{e} 10$. J. Virol. 89, 11975-11989 (2015).

48. Zanetti, G., Briggs, J.A., Grunewald, K., Sattentau, Q.J. \& Fuller, S.D. Cryo-electron tomographic structure of an immunodeficiency virus envelope complex in situ. PLoS Pathog. 2, e83 (2006).

49. Kucukelbir, A., Sigworth, F.J. \& Tagare, H.D. Quantifying the local resolution of cryo-EM density maps. Nat. Methods 11, 63-65 (2014). 


\section{ONLINE METHODS}

Materials and reagents. All detergents were purchased from Affymetrix. Luria-Bertani broth, Miller and Terrific broth were from Formedium. Kanamycin was obtained from Duchefa Biochemie. IPTG (isopropyl $\beta$-D-1-thiogalactopyranoside) was from Saveen Werner. Soluble human CD4 (4d-CD4) was obtained from Invitrogen. The PG16 and $17 \mathrm{~b}$ Fab antibodies ${ }^{31}$ were obtained from the US National Institutes of Health AIDS Research and Reference Reagent Program. We generated Fab fragments for ligand binding studies by digesting $18 \mu \mathrm{g}$ of monoclonal antibody in $25 \mu \mathrm{l}$ of phosphate-buffered saline (PBS) containing $10 \mathrm{mM}$ EDTA, $5 \mathrm{mM}$ Cys, and $0.5 \mu \mathrm{g}$ of papain for $4 \mathrm{~h}$ at $37^{\circ} \mathrm{C}$. The digestion was terminated by the addition of iodoacetamide to $5 \mathrm{mM}$. Samples were diluted with $175 \mu \mathrm{l}$ of HNC buffer ( $50 \mathrm{mM}$ HEPES, $100 \mathrm{mM} \mathrm{NaCl}, 1.8 \mathrm{mM} \mathrm{CaCl}_{2}, \mathrm{pH}$ 7.4), and uncleaved antibodies and $\mathrm{Fc}$ fragments were removed by binding to protein A-Sepharose (GE Healthcare, Uppsala, Sweden) overnight at $4{ }^{\circ} \mathrm{C}$. All other chemicals were from Sigma-Aldrich, unless otherwise stated.

Expression and purification of saposin A. Protein expression was carried out using a vector with the coding region for saposin A inserted into a pNIC-Bsa4 plasmid. The cloning vector pNIC28-Bsa4 adds an N-terminal hexahistidine tag with an integrated TEV protease cleavage site. The cleaved target protein represents the saposin A polypeptide with three additional N-terminal Ser-Met-Gly residues as a result of the cloning strategy, with the protein sequence MHHHHHHSSGVDLGTENLYFQSMGSLP CDICKDVVTAAGDMLKDNATEEEILVYLEKTCDWLPKPNM SASCKEIVDSYLPVILDIIKGEMSRPGEVCSALNLCES. The protein was expressed using E. coli Rosetta gami-2 (DE3) (Novagen). Cells were grown at $37^{\circ} \mathrm{C}$ in Terrific broth supplemented with tetracycline, chloramphenicol and kanamycin and induced with $0.7 \mathrm{mM}$ IPTG. Three hours after induction we collected the cells by centrifugation at $12,000 \mathrm{~g}$ for $15 \mathrm{~min}$; we discarded the supernatant. The cell pellet was resuspended in lysis buffer $(20 \mathrm{mM}$ HEPES, pH 7.5, $150 \mathrm{mM} \mathrm{NaCl}, 20 \mathrm{mM}$ imidazole) and disrupted by sonication. Lysates were subjected to centrifugation at $26,000 \mathrm{~g}$ for $30 \mathrm{~min}$, and the supernatant was heated to $85^{\circ} \mathrm{C}$ for $10 \mathrm{~min}$ and then subjected to an additional centrifugation step at $26,000 \mathrm{~g}$ for $30 \mathrm{~min}$. Preparative immobilized metal affinity chromatography (IMAC) purification consisted of batch-adsorption of the supernatant by end-over-end rotation with Ni Sepharose 6 Fast Flow medium for $60 \mathrm{~min}$. After binding of saposin A to the IMAC resin, the chromatography medium was packed in a 10 -mm innerdiameter open gravity flow column, and unbound proteins were removed by washing with 15 bed volumes of lysis buffer. The resin was washed with 15 bed volumes of wash buffer WB2 $(20 \mathrm{mM}$ HEPES, pH 7.5, $150 \mathrm{mM} \mathrm{NaCl}, 40 \mathrm{mM}$ imidazole). Saposin was eluted by the addition of five bed volumes of elution buffer EB (20 mM HEPES, pH 7.5, $150 \mathrm{mM} \mathrm{NaCl}, 400 \mathrm{mM}$ imidazole). The eluate was dialyzed overnight against gel filtration buffer GF (20 mM HEPES, pH 7.5, $150 \mathrm{mM} \mathrm{NaCl}$ ) supplemented with recombinant TEV protease. We removed TEV protease containing an uncleavable His-tag from the eluate by passing the eluate over $2 \mathrm{ml}$ of IMAC resin. Cleaved target protein was concentrated to a volume of $5 \mathrm{ml}$ using centrifugal filter units and loaded onto a HiLoad Superdex 200 16/60 GL column using an ÄKTAexplorer 10 chromatography system. Peak fractions were pooled and concentrated to $1.2 \mathrm{mg} / \mathrm{ml}$ protein. Typically, a 1-l bacterial culture yields 5-10 mg of purified saposin. The protein sample was flash-frozen in liquid nitrogen and stored at $-80^{\circ} \mathrm{C}$.

Expression and purification of POT and T2. POT was expressed and purified according to a recently described protocol ${ }^{18,19}$. T2 was purified as described recently ${ }^{17}$.

Generation of Salipro lipid particles. We prepared detergentsolubilized lipids by dissolving the respective lyophilized lipid powder (brain lipid mix from bovine brain from Sigma-Aldrich; phosphatidylserine, phosphatidylcholine, phosphatidylglycerol, phosphatidylethanolamine and E. coli total lipid extract from Avanti Polar Lipids) in buffer D (50 mM HEPES, pH 7.5, $150 \mathrm{mM} \mathrm{NaCl}, 1 \% n$-dodecyl- $\beta$-D-maltoside (DDM)) to obtain a stock solution that contained $25 \mathrm{mg} / \mathrm{ml}$ lipids and then incubated it for $1 \mathrm{~h}$ at $37^{\circ} \mathrm{C}$. If not otherwise stated, a brain lipid extract from bovine brain, Type I (Sigma-Aldrich) was used for nanoparticle generation. Prior to Salipro particle reconstitution, the lipid stock solutions were diluted to $5 \mathrm{mg} / \mathrm{ml}$ using buffer E (50 mM HEPES, pH 7.5, $150 \mathrm{mM} \mathrm{NaCl,} \mathrm{0.03 \%} \mathrm{DDM).} \mathrm{For}$ the reconstitution of Salipro particles, $10 \mu \mathrm{l}$ of purified saposin $\mathrm{A}$ and $5 \mu \mathrm{l}$ of the respective detergent-solubilized lipids were incubated for $10 \mathrm{~min}$ at $37^{\circ} \mathrm{C}$. Subsequently, $50 \mu \mathrm{l}$ of GF buffer was added to the mixture and incubated for $10 \mathrm{~min}$ at room temperature. The reconstitution mixture was subjected to a gel filtration analysis on a Superdex S200 5/150 analytical gel filtration column (GE Healthcare) and eluted with GF buffer, giving rise to a monodisperse peak of Salipro particles. For a mediumscale preparation, $60 \mu \mathrm{l}$ of a brain lipid solution $(5 \mathrm{mg} / \mathrm{ml}$ brain lipids (Sigma-Aldrich), $50 \mathrm{mM}$ HEPES, pH 7.5, $150 \mathrm{mM} \mathrm{NaCl}$, $0.28 \% \mathrm{DDM})$ were incubated with $100 \mu \mathrm{l}$ of purified saposin A (1.2 mg/ml, $20 \mathrm{mM}$ HEPES, pH 7.5, $150 \mathrm{mM} \mathrm{NaCl}$ ) and incubated for $5 \mathrm{~min}$ at $37^{\circ} \mathrm{C}$, after which $160 \mu \mathrm{l}$ of GF buffer was added and the mixture was incubated for $10 \mathrm{~min}$ at room temperature. Then $230 \mu \mathrm{l}$ of GF buffer were added and the sample was subjected to a gel filtration step on a Superdex200 10/300 GL column using an ÄKTAexplorer 10 chromatography system equilibrated with GF buffer. Fractions containing Salipro particles were pooled and concentrated to $1 \mathrm{mg} / \mathrm{ml}$ using Amicon Centricon filter devices at 3,000g.

In one experiment, Salipro particles were generated after incubation with an increasing excess of lipids. Here varying amounts of lipid (Lipids 5, $5 \mu \mathrm{g}$; Lipids 12.5, $12.5 \mu \mathrm{g}$; Lipids 25, $25 \mu \mathrm{g}$; Lipids 50, $50 \mu \mathrm{g}$; Lipids 100, $100 \mu \mathrm{g}$ ) from a brain lipid solution ( $5 \mathrm{mg} / \mathrm{ml}$ brain lipids (Sigma-Aldrich), $50 \mathrm{mM}$ HEPES, $\mathrm{pH}$ $7.5,150 \mathrm{mM} \mathrm{NaCl}, 0.28 \% \mathrm{DDM}$ ) were incubated for $10 \mathrm{~min}$ at $37^{\circ} \mathrm{C} .10 \mu \mathrm{l}$ of purified saposin A $(1.2 \mathrm{mg} / \mathrm{ml}, 20 \mathrm{mM}$ HEPES, $\mathrm{pH} 7.5,150 \mathrm{mM} \mathrm{NaCl}$ ) were added and incubated for $1 \mathrm{~min}$ at $37^{\circ} \mathrm{C}$, and GF buffer was added to a final volume of $41 \mu \mathrm{l}$. After $10 \mathrm{~min}$ of incubation at room temperature, $24 \mu \mathrm{l}$ of GF buffer ( $\mathrm{pH} 7.5$ ) were added and the samples were subjected to a gel filtration step on a SuperdexTM 200 5/150 GL analytical gel filtration column using an ÄKTAmicro chromatography system (both GE Healthcare) equipped with the A-905 autosampler, which automatically injected $25 \mu \mathrm{l}$ of protein-containing sample. Analytical gel filtration runs were performed at $4{ }^{\circ} \mathrm{C}$ at a flow rate of $0.2 \mathrm{ml} / \mathrm{min}$ in GF buffer. 
Incorporation of membrane proteins into Salipro particles. To reconstitute the archaeal mechanosensitive channel T2 in Salipro nanoparticles, we incubated $5 \mu \mathrm{l}$ of a brain lipid solution $(5 \mathrm{mg} / \mathrm{ml}$ brain lipids (Sigma-Aldrich), $50 \mathrm{mM}$ HEPES, pH 7.5, $150 \mathrm{mM}$ $\mathrm{NaCl}, 0.28 \% \mathrm{DDM}$ ) for $5 \mathrm{~min}$ at $37^{\circ} \mathrm{C}$, after which we added $2 \mu \mathrm{l}$ of purified membrane protein T2 $(10 \mathrm{mg} / \mathrm{ml}, 20 \mathrm{mM}$ Tris- $\mathrm{HCl}$, pH 7.5, $150 \mathrm{mM} \mathrm{NaCl}, 5 \%$ glycerol, $0.03 \%$ DDM) subjected the samples to a second incubation step at $37{ }^{\circ} \mathrm{C}$. Subsequently, we added $20 \mu \mathrm{l}$ of purified saposin A $(1.2 \mathrm{mg} / \mathrm{ml}, 20 \mathrm{mM}$ HEPES, $\mathrm{pH} 7.5,150 \mathrm{mM} \mathrm{NaCl}$ ) and incubated the samples for $5 \mathrm{~min}$ at $37^{\circ} \mathrm{C}$. Then we added $24 \mu \mathrm{l}$ of $1 \times \mathrm{PBS}(\mathrm{pH} 7.4$ ) and incubated the mixture for $5 \mathrm{~min}$ at room temperature, after which we added $39 \mu \mathrm{l}$ of $1 \times$ PBS ( $\mathrm{pH} 7.4$ ) to the mixture. The sample was subjected to a gel-filtration step on a Superdex S200 5/150 analytical gel filtration column, equilibrated and eluted with $1 \times \mathrm{PBS}(\mathrm{pH} 7.4)$.

For a medium-scale preparation of Salipro-T2, we incubated $40 \mu \mathrm{l}$ of a brain lipid solution ( $5 \mathrm{mg} / \mathrm{ml}$ brain lipids (SigmaAldrich), 50 mM HEPES, pH 7.5, 150 mM NaCl, 0.28\% DDM) and $5 \mu \mathrm{l}$ of protease inhibitor stock solution (1 cOmplete EDTAfree tablet in $1 \mathrm{ml} \mathrm{H}_{2} \mathrm{O}$ ) for $5 \mathrm{~min}$ at $37^{\circ} \mathrm{C}$, added $20 \mu \mathrm{l}$ of purified membrane protein $\mathrm{T} 2(10 \mathrm{mg} / \mathrm{ml}, 20 \mathrm{mM}$ Tris- $\mathrm{HCl}, \mathrm{pH} 7.5$, $150 \mathrm{mM} \mathrm{NaCl}, 5 \%$ glycerol, $0.03 \%$ DDM) and subjected the mixture to a second incubation step at $37^{\circ} \mathrm{C}$. Subsequently, we added $140 \mu \mathrm{l}$ of purified saposin A ( $1.2 \mathrm{mg} / \mathrm{ml}, 20 \mathrm{mM}$ HEPES, pH 7.5, $150 \mathrm{mM} \mathrm{NaCl}$ ) and incubated the mixture for $5 \mathrm{~min}$ at $37^{\circ} \mathrm{C}$. Then we added $145 \mu$ l of $1 \times$ PBS ( $\mathrm{pH} 7.4$ ) and incubated the mixture for $5 \mathrm{~min}$ at room temperature, after which we added $150 \mu \mathrm{l} 1 \times$ PBS. The sample was subjected to a gel filtration step on a Superdex200 10/300 GL column using an ÄKTAexplorer 10 chromatography system equilibrated with $1 \times \mathrm{PBS}(\mathrm{pH} 7.4)$. Fractions containing Salipro-T2 were pooled and concentrated to $1 \mathrm{mg} / \mathrm{ml}$ using Amicon Centricon filter devices at 3,000g. The protein sample was flash-frozen in liquid nitrogen and stored at $-80{ }^{\circ} \mathrm{C}$ until further use.

To reconstitute the bacterial peptide transporter POT in Salipro nanoparticles, we incubated $5 \mu \mathrm{l}$ of a brain lipid solution ( $5 \mathrm{mg} / \mathrm{ml}$ brain lipids (Sigma-Aldrich), $50 \mathrm{mM} \mathrm{HEPES,} \mathrm{pH} \mathrm{7.5,}$ $150 \mathrm{mM} \mathrm{NaCl}, 0.28 \% \mathrm{DDM}$ ) for $5 \mathrm{~min}$ at $37^{\circ} \mathrm{C}$, added $2 \mu \mathrm{l}$ of purified membrane protein POT $(10 \mathrm{mg} / \mathrm{ml}, 20 \mathrm{mM}$ Tris- $\mathrm{HCl}$, $\mathrm{pH} 7.5,150 \mathrm{mM} \mathrm{NaCl}, 5 \%$ glycerol, $0.4 \% \mathrm{NM}$ ) and subjected the mixture to a second incubation step at $37^{\circ} \mathrm{C}$. Subsequently, we added $15 \mu \mathrm{l}$ of purified saposin A $(1.2 \mathrm{mg} / \mathrm{ml}, 20 \mathrm{mM}$ HEPES, $\mathrm{pH} 7.5,150 \mathrm{mM} \mathrm{NaCl}$ ) and incubated the mixture for $5 \mathrm{~min}$ at $37^{\circ} \mathrm{C}$. Then we added $19 \mu \mathrm{l}$ of $1 \times \mathrm{PBS}(\mathrm{pH} 7.4$ ) and incubated the mixture for $5 \mathrm{~min}$ at room temperature, after which we added $39 \mu \mathrm{l}$ of $1 \times$ PBS ( $\mathrm{pH} 7.4$ ). The sample was subjected to a gel filtration step on a Superdex S200 5/150 analytical gel filtration column, equilibrated and eluted with $1 \times \mathrm{PBS}(\mathrm{pH} 7.4)$.

For a medium-scale preparation of Salipro-POT, we incubated $40 \mu \mathrm{l}$ of a brain lipid solution $(5 \mathrm{mg} / \mathrm{ml}$ brain lipids (SigmaAldrich), 50 mM HEPES, pH 7.5, 150 mM NaCl, 0.28\% DDM) for $5 \mathrm{~min}$ at $37^{\circ} \mathrm{C}$, added $20 \mu \mathrm{l}$ of purified membrane protein POT (10 mg/ml, 20 mM Tris- $\mathrm{HCl}, \mathrm{pH} 7.5,150 \mathrm{mM} \mathrm{NaCl}, 5 \%$ glycerol, $0.4 \% \mathrm{NM}$ ) and subjected the mixture to a second incubation step at $37^{\circ} \mathrm{C}$. Subsequently, we added $100 \mu \mathrm{l}$ of purified saposin A (1.2 mg/ml, $20 \mathrm{mM}$ HEPES, $\mathrm{pH} 7.5,150 \mathrm{mM} \mathrm{NaCl}$ ) and incubated the mixture for $5 \mathrm{~min}$ at $37^{\circ} \mathrm{C}$. Then we added $150 \mu \mathrm{l}$ of $1 \times \mathrm{PBS}$ ( $\mathrm{pH} 7.4$ ) and incubated the mixture for $5 \mathrm{~min}$ at room temperature, after which we added $220 \mu \mathrm{l}$ of $1 \times$ PBS. The sample was subjected to a gel filtration step on a Superdex200 10/300 GL column using an ÄKTAexplorer 10 chromatography system equilibrated with $1 \times$ PBS (pH 7.4), 5\% glycerol. Fractions containing Salipro-POT were pooled and concentrated to $0.7 \mathrm{mg} / \mathrm{ml}$ using Amicon Centricon filter devices at $3,000 \mathrm{~g}$. The protein sample was flash-frozen in liquid nitrogen and stored at $-80{ }^{\circ} \mathrm{C}$ until further use.

In one experiment, we tested the effect of $\mathrm{pH}$ on POT reconstitution in Salipro particles. Here, to reconstitute the bacterial peptide transporter POT in Salipro nanoparticles, we incubated $18 \mu \mathrm{l}$ of a brain lipid solution $(5 \mathrm{mg} / \mathrm{ml}$ brain lipids (SigmaAldrich), $50 \mathrm{mM}$ HEPES, pH 7.5, $150 \mathrm{mM} \mathrm{NaCl}, 0.28 \%$ DDM) for $5 \mathrm{~min}$ at $37^{\circ} \mathrm{C}$, added $5 \mu \mathrm{l}$ of purified membrane protein POT (10 mg/ml, 20 mM Tris-HCl, pH 7.5, 150 mM NaCl, 5\% glycerol, $0.03 \% \mathrm{DDM}$ ) and subjected the mixture to a second incubation step at $37^{\circ} \mathrm{C}$. Subsequently, we added $80 \mu$ l of purified saposin A (1.2 mg/ml, $20 \mathrm{mM} \mathrm{HEPES,} \mathrm{pH} 7.5,150 \mathrm{mM} \mathrm{NaCl})$ and incubated the mixture for $5 \mathrm{~min}$ at $37^{\circ} \mathrm{C}$. We transferred this mixture into individual tubes ( $23 \mu \mathrm{l}$ in each tube) and added $50 \mu \mathrm{l}$ of buffers with various $\mathrm{pH}$ levels to the tubes $(\mathrm{pH}$ 4.5: $20 \mathrm{mM}$ trisodium citrate, $100 \mathrm{mM} \mathrm{NaCl}$; $\mathrm{pH}$ 6: $20 \mathrm{mM}$ trisodium citrate, $100 \mathrm{mM}$ $\mathrm{NaCl}$; pH 7.5: $20 \mathrm{mM}$ Tris- $\mathrm{HCl}, 100 \mathrm{mM} \mathrm{NaCl}$; pH 9: $20 \mathrm{mM}$ Tris- $\mathrm{HCl}, 100 \mathrm{mM} \mathrm{NaCl}$ ). After $5 \mathrm{~min}$ of incubation, the samples were subjected to a gel filtration step on a Superdex S200 $5 / 150$ analytical gel filtration column, equilibrated and eluted with buffers at the corresponding $\mathrm{pH}$ (4.5-9).

Negative-stain electron microscopy. For Salipro lipid-only discs, carbon-coated copper grids (400 mesh) were glow discharged in low-pressure air to render them hydrophilic for $20 \mathrm{~s}$ before application of $4 \mu \mathrm{l}$ sample for $30 \mathrm{~s}$. Washing was done with three drops of water before staining with $4 \mu \mathrm{l}$ of uranyl formate ( $1 \%$, Polysciences, USA) for $30 \mathrm{~s}$. The grids were air dried after the removal of excess stain solution with torn filter paper. Negativestain image data were collected with a JEOL2100F field emission gun transmission electron microscope at an accelerating voltage of $200 \mathrm{kV}$ and a final magnification of $69,500 \times$ on a CCD (charge-coupled device) camera $(4 \mathrm{~K} \times 4 \mathrm{~K}$, Tietz Video and Image Processing System, GmbH Gauting, Germany) with $15-\mu \mathrm{m}$ pixel size (corresponding to $2.16 \AA$ on the specimen level).

Salipro-T2 samples were stained with uranyl acetate and imaged on an FEI TECNAI Polara TEM at $100 \mathrm{kV}$ at a magnification of 59,000× and a pixel size of $1.91 \AA ̊$ on an UltraScan 4000 CCD camera (Gatan). Individual particles were windowed semiautomatically with the swarm option of e2boxer (EMAN2 package ${ }^{50}$ ). After normalization, 33,000 particles were subjected to reference-free $2 \mathrm{D}$ classification and class averaging using the EMAN2 routines (e2refine2d).

Thermal unfolding analysis. Thermal unfolding analysis was performed using dye-free differential scanning fluorimetry ${ }^{20}$ using two samples each for POT in detergent (1× PBS, pH 7.4, $0.4 \% \mathrm{NM})$ and Salipro-POT $(1 \times \mathrm{PBS}, \mathrm{pH} 7.4)$ with a sample volume of $10 \mu \mathrm{l}$ per capillary at a concentration of $0.2 \mathrm{mg} / \mathrm{ml}$. The temperature was increased by $1^{\circ} \mathrm{C} / \mathrm{min}$ from $20^{\circ} \mathrm{C}$ to $95^{\circ} \mathrm{C}$ using a Prometheus NT.48 instrument (Nanotemper).

Cryo-EM. The POT data were collected and processed as described $^{51}$. We applied $2.5 \mu$ l of purified sample at $0.7 \mathrm{mg} / \mathrm{ml}$ concentration to a glow discharged Quantifoil holey carbon grid 
(400 mesh, $1.2-\mu \mathrm{m}$ hole size) and blotted it at $100 \%$ humidity using the FEI Vitrobot Mark I for $5.5 \mathrm{~s}$. A total of 288 images of the vitrified sample were subsequently collected on an FEI TF30 Polara electron microscope operated at $300 \mathrm{kV}$, equipped with a Gatan K2 Summit direct electron detector camera. The images were recorded with a defocus in a range from 1.5 to $2.5 \mu \mathrm{m}$ at a nominal magnification of $31,000 \times$, corresponding to a calibrated physical pixel size of $1.2156 \AA$ /pixel on the specimen at a dose rate on the camera set to 8.2 counts per physical pixel per second. The sample was exposed for a total time of $6 \mathrm{~s}$, with each image fractionated into 30 subframes, each with an accumulation time of $0.2 \mathrm{~s}$ per frame, with a total accumulated dose of $41 \mathrm{e}-/ \AA^{2}$ on the specimen.

Image processing. Dose-fractionated super-resolution image frames were drift-corrected using whole-frame motion correction $^{22}$; a sum of all subframes in each image stack was used for further processing. The particles embedded in vitreous ice were monodisperse and exhibited good contrast (Fig. 3a), even at low defocus.

For all 2D image display and particle picking, we used SamViewer, an interactive image-analysis program written in Python. Defocus was determined using CTFFIND4 (ref. 52). Particle extraction and class averaging were performed in RELION ${ }^{53}$. Using 12,200 particles, we performed 2D classification (Fig. 3b) and obtained classes with a large number of inner-membrane details. Selected classes were extracted, and a probabilistic initial 3D-model generation procedure (PRIME) implemented in the SIMPLE ${ }^{54}$ package was used for $a b$ initio $3 \mathrm{D}$-reconstruction generation; this served as a reference model for the maximum likelihood-based 3D classification and autorefinement procedure implemented in RELION. For the final 3D reconstruction (Fig. 4a,b), 9,913 particles were used and C4 symmetry was imposed; resolutions were estimated using the FSC 0.143 criterion $^{23}$ on corrected FSC curves to obtain the map at $6.48 \AA$ (Fig. 3e). ResMap was used to estimate local resolution from the unbinned and unsharpened raw density map ${ }^{49}$. Figures were prepared using UCSF Chimera ${ }^{55}$.

HIV virus-like particle production. VLPs carrying HIV-1 JRFL spikes with a deleted cytoplasmic tail (truncated at residue 708), disulfide-linked gp120 and gp41 (Cys501-Cys605), and E168K and N189A mutations (which facilitate binding of PG16 to the JR-FL spike) were produced in HEK 293T cells by calcium phosphate precipitation-mediated cotransfection. For production of [35S]Cys-labeled VLPs, we transfected one $150-\mathrm{cm}^{2}$ culture flask of semiconfluent $293 \mathrm{~T}$ cells using $10 \mu \mathrm{g}$ of pCAGGS JRFL gp160SOS, $\Delta$ CT,E168K,N189A and $10 \mu \mathrm{g}$ of pNL4-3.Luc.R-E $\mathrm{DNA}^{56,57}$. [35S]Cys was incorporated into the VLPs through metabolic labeling in Cys-free Dulbecco's modified Eagle's medium (National Veterinary Institute, Uppsala, Sweden) supplemented with $10 \mu \mathrm{M}$ unlabeled Cys and $100 \mu \mathrm{Ci}$ of [35S]Cys/ml (Fisher Scientific, Gothenburg, Sweden) from 24 to $48 \mathrm{~h}$ after the transfection. Cell debris was removed from the virus-contain media using low-speed centrifugation at 1,000 r.p.m. for $10 \mathrm{~min}$. The cleared supernatant was layered on top of a step gradient composed of $1 \mathrm{ml}$ of $60 \%$ sucrose and $4.5 \mathrm{ml}$ of $20 \%$ sucrose (wt/wt) in $\mathrm{HN}$ buffer ( $50 \mathrm{mM}$ HEPES, $100 \mathrm{mM} \mathrm{NaCl}, \mathrm{pH}$ 7.4) and centrifuged at $4{ }^{\circ} \mathrm{C}$ for $2 \mathrm{~h}$ at $93,000 \mathrm{~g}(22,000$ r.p.m.) in a Beckman
SW28.1 rotor. Radiolabeled virus was collected from the $20 / 60 \%$ sucrose interphase. For unlabeled VLP production, 15 culture flasks $\left(150 \mathrm{~cm}^{2}\right)$ with 293 T cells were transfected, and the virus was collected and concentrated as described above. To increase VLP concentration, we diluted the virus to $15-20 \%$ sucrose in HN buffer and added it on top of a 1-ml 60\% (wt/wt) sucrose cushion, after which we subjected it to a second ultracentrifugation step at $4{ }^{\circ} \mathrm{C}$ for $6 \mathrm{~h}$ at 22,000 r.p.m. using the SW28.1 rotor. The virus was collected by fractionation from the bottom, and fractions were analyzed using SDS-PAGE and SYPRO Ruby protein stain to visualize the VLP peak for collection.

Incorporation of the trimeric HIV-1 spike into Salipro nanoparticles. VLPs were lysed for $10 \mathrm{~min}$ on ice in HN buffer supplemented with $9 \mathrm{mM}$ HEGA-10 in the presence of saposin A, and in some cases brain lipids. HEGA-10 was then removed by two successive spin SEC steps (Zeba spin desalting columns, $7 \mathrm{~K}$ MWCO). The columns were washed and centrifuged according to the manufacturer's instructions (Pierce). The column removed the HEGA-10 detergent but not saposin A, which with viral lipids replace the detergent in the spike-detergent complexes. Salipro-HIV spike particles eluted from the column void volume together with the other soluble virus proteins. The sample was then incubated for $15 \mathrm{~min}$ at $37^{\circ} \mathrm{C}$ before lectin purification of the Salipro-HIV spike particles.

Purification of the Salipro-HIV spike particles. Salipro-HIV spikes were purified using Galanthis Nivalis lectin (Sigma-Aldrich) affinity chromatography. The lectin binds to high-mannose sugar moieties on the spike protein. The column was washed with 50 column volumes of HN buffer, and then the Salipro-HIV spike particles were eluted using $0.3 \mathrm{M}$ methyl- $\alpha$-D-mannopyranoside. The methyl- $\alpha-\mathrm{D}$-mannopyranoside was removed from the sample using a spin SEC column (Zeba spin desalting columns, 7K MWCO) and replaced with HN buffer. The SaliproHIV spikes were concentrated by ultrafiltration using an Amicon Ultra-4 50K MWCO centrifugation filter (Millipore), and sample purity was assayed with SDS-PAGE using SYPRO Ruby protein staining (Lonza Group) and BN-PAGE using silver staining (Thermo Scientific).

Functional assays of the Salipro-HIV spikes. Salipro-HIV spike particles were incubated with $10 \mu \mathrm{g} / \mathrm{ml}$ of PG16, sCD4 or $17 \mathrm{~b}$ Fab in $\mathrm{HN}$ buffer for $2 \mathrm{~h}$ at $37^{\circ} \mathrm{C}$. The formation of ligand spike complexes was followed by BN-PAGE and phosphorimaging. One volume of two times-concentrated BN-PAGE sample buffer was added, and the samples were incubated for $10 \mathrm{~min}$ at room temperature and analyzed by gradient BN-PAGE with $3-8 \%$ total acrylamide as described previously ${ }^{58}$. The dried gels were exposed to phosphorimage screens (BAS MS2025; Fujifilm, Science Imaging, Nacka, Sweden), and the radiolabeled bands were visualized using a Molecular Imager FX and the Quantity One software (Bio-Rad, Hercules, CA).

50. Tang, G. et al. EMAN2: an extensible image processing suite for electron microscopy. J. Struct. Biol. 157, 38-46 (2007).

51. Liao, M., Cao, E., Julius, D. \& Cheng, Y. Structure of the TRPV1 ion channel determined by electron cryo-microscopy. Nature 504, 107-112 (2013). 
52. Rohou, A. \& Grigorieff, N. CTFFIND4: fast and accurate defocus estimation from electron micrographs. bioRxiv doi:10.1101/020917 (13 August 2015).

53. Scheres, S.H. RELION: implementation of a Bayesian approach to cryo-EM structure determination. J. Struct. Biol. 180, 519-530 (2012).

54. Elmlund, D. \& Elmlund, H. SIMPLE: software for ab initio reconstruction of heterogeneous single-particles. J. Struct. Biol. 180, 420-427 (2012).

55. Pettersen, E.F. et al. UCSF Chimera-a visualization system for exploratory research and analysis. J. Comput. Chem. 25, 1605-1612 (2004).
56. Moore, P.L. et al. Nature of nonfunctional envelope proteins on the surface of human immunodeficiency virus type 1. J. Virol. 80, 2515-2528 (2006).

57. Wu, S.R. et al. Single-particle cryoelectron microscopy analysis reveals the HIV-1 spike as a tripod structure. Proc. Natl. Acad. Sci. USA 107, 18844-18849 (2010).

58. Löving, R., Wu, S.R., Sjoberg, M., Lindqvist, B. \& Garoff, H. Maturation cleavage of the murine leukemia virus Env precursor separates the transmembrane subunits to prime it for receptor triggering. Proc. Natl. Acad. Sci. USA 109, 7735-7740 (2012). 